\title{
CORRELATION OF BODY MEASUREMENTS AND EXERCISE WITH BLOOD PRESSURE AMONG MEDICAL STUDENTS IN LAHORE
}

\author{
Iram Manzoor, Aneeqa Mumtaz, Iqra Mushtaq \\ Akhtar Saeed Medical and Dental College, Lahore Pakistan
}

\begin{abstract}
Objective: To find out correlation of body measurements and exercise with blood pressure among medical students in Lahore, Pakistan.

Study Design: Correlational study.

Place and Duration of Study: Akhtar Saeed Medical and Dental College, Lahore, from May to Jul 2018.

Methodology: A sample of 332 students was recruited through simple random sampling technique. Resting blood pressure in sitting position along with body mass index of respondents were taken after informed consent.

Results: Mean age of respondents was $21.06 \pm 1.53$ years. Mean sitting systolic blood pressure was $117.5 \pm 8.24 \mathrm{~mm} \mathrm{Hg}$, Mean sitting diastolic blood pressure was $77.9 \pm 7.05 \mathrm{~mm} \mathrm{Hg}$. Significant association was found between weight and both Systolic $(\mathrm{r}=1, p \leq 0.00)$ and Diastolic $(\mathrm{r}=0.01, p=0.05)$ blood pressure. Height was negatively correlated with systolic blood pressure $(\mathrm{r}=-0.004)$ and diastolic blood pressure $(\mathrm{r}=-0.07)$. Body mass index was also significantly associated with systolic blood pressure $(\mathrm{r}=1, p \leq 0.00)$ and diastolic blood pressures $(\mathrm{r}=0.14, p=0.00)$. Significant association is found between systolic blood pressure and exercise with number of days $(\mathrm{r}=-0.15, p=0.05)$ and diastolic blood pressure $(\mathrm{r}=-0.11, p=0.00)$ and duration of exercise with systolic blood pressure $(\mathrm{r}=-0.13, p=0.01)$ and diastolic blood pressure $(\mathrm{r}=-0.16, p=0.04)$.

Conclusion: Weight and Body mass index are positively correlated with systolic and diastolic blood pressure.
\end{abstract}

Keywords: Blood pressure, Body mass index, Exercise, Weight.

How to Cite This Article: Manzoor I, Mumtaz A, Mushtaq I. Correlation of Body Measurements and Exercise with Blood Pressure Among Medical Students in Lahore. Pak Armed Forces Med J 2021; 71(5): 1889-1892. ～doi: https://doi.org/10.51253/pafmj.v71i5.6089

This is an Open Access article distributed under the terms of the Creative Commons Attribution License (https://creativecommons.org/licenses/by-nc/4.0/), which permits unrestricted use, distribution, and reproduction in any medium, provided the original work is properly cited.

\section{INTRODUCTION}

Hypertension is one of the known diseases of public health importance, associated with high mortality and disability worldwide. ${ }^{1}$ Recent statistics of WHO show that global prevalence of this non-communicable disease exceeds 1.3 billion. $^{2}$ It is expected that in coming five years, prevalence of this disease to be expected to increase by $9 \%$ in men and $13 \%$ in women due to change in population dynamics. ${ }^{3}$ Existence of hypertension in youth is associated with severe consequences resulting from cardio vascular accidents. Prehypertension leading to hypertension, has greatest global share of deaths from cardiovascular, cerebral (stroke), and renal disease. ${ }^{4}$ The prevalence of hypertension was $17.9 \%$ in Bangladesh; $23.9 \%$ in Bhutan; $31.4 \%$ in India; $31.5 \%$ in Maldives; $33.8 \%$ in Nepal; $25 \%$ in Pakistan; and $20.9 \%$ in Sri Lanka. ${ }^{5}$

Hypertension is not only the dilemma of developed countries but it trickles down to the countries with lower socioeconomic status too. A study was conducted in Nigerian schools which showed that $4.7 \%$ of the

Correspondence: Dr Iram Manzoor, 80-Bulevard, Sector C, Tulip Block Bahria Town, Lahore Pakistan

Received: 11 Jan 2021; revision received: 23 Jun 2021; accepted: 29 Jun 2021 school children were diagnosed with stage I hypertension. ${ }^{6}$ Multiple predictors of hypertension include old age, weight, height, BMI, salt intake, smoking, exercise routine, family history and stress. ${ }^{7}$ A study was conducted in Ethiopia on 2200 participants revealed that association of hypertension with old age, diabetes, alcohol consumption and high BMI. ${ }^{8}$

A study conducted in Faisalabad, Pakistan in 2017 among medical students showed high BMI and stress has strong association with pre-hypertension. ${ }^{9}$ It is important to identify hypertension in younger population and to track them in future to avoid associated comorbidities. ${ }^{10}$ There is dearth of knowledge about prevalence of hypertension in college and university students in Pakistan. This study aims to find out prevalence of hypertension among students of a medical university and correlate its presence with multiple risk factors associated with it.

\section{METHODOLOGY}

Written informed consent was taken from study participants along with the Ethical approval from Institutional Review Board (Ref no. M-19/048/CM). This cross-sectional study was conducted among students of Akhtar Saeed Medical and Dental College 
(AMDC) from May to July 2018. Rao soft sample size calculator was used for sample size estimation. A sampling frame was constructed including all the students of AMDC (1500). A sample size of 306 was calculated keeping confidence level of $95 \%$, margin of error $5 \%$ and prevalence taken was $32 \%$ from the study conducted in year 2017 in Ghana. ${ }^{11}$ A sample of 332 students was recruited by using simple random sampling technique through computer-generated numbers. In order to overcome deficient information or errors in recording information, 32 students were added to make a sample size of 340 . On data cleaning, 332 questionnaires were found fit for analysis.

Inclusion Criteria: All the students studying in AMDC constituent colleges were included in the study.

Exclusion Criteria: Those students, who are already hypertensive, were excluded from the study.

A questionnaire designed for this study was pretested and after necessary changes modified for final data collection. All the students were briefed about administration of the questionnaire. Resting blood pressure in sitting position and body mass index of the respondents was measured, calculated, and recorded in the questionnaire in addition to other information collected.

The data collected was reviewed for quality assurance and subsequently after coding of the questionnaire, entered into Statistical Package for Social Sciences (SPSS) for analysis of results. verbal consent was taken from all respondents and only those respondents were interviewed and their blood pressure checked who agreed to participate in this study. Furthermore, all matters related to ethical conduction of the study with confidentiality of the respondents was observed. After data entry, Pearson's correlation model was applied between factors affecting blood pressure. Correlation was agreed upon with values of $r$ ranging between $(-1,0,+1)$ and $p$-values were considered at $\leq 0.05$ for significant associations.

\section{RESULTS}

Among 332 students taken as sample 109 (33\%) were males and $223(67 \%)$ were females. Students were categorized according to age group and maximum response was obtained from group ranging from 21-24 years include 205 students (61\%). Among 332 students $256(77 \%)$ were MBBS students. Out of these 332 students, $167(50.3 \%)$ students had a positive family history of hypertension (Table-I).
Mean age of respondents was $21.06 \pm 1.53$ years. Mean sitting systolic blood pressure was $117.5 \pm 8.24$ $\mathrm{mm} \mathrm{Hg}$, Mean sitting diastolic blood pressure was 77.9 $\pm 7.05 \mathrm{~mm} \mathrm{Hg}$. Mean weight and height were respectively observed as $62.77 \pm 12.60$ in $\mathrm{kg}$ and $1.65 \pm 0.11$ in meters. Out of 332 participants, only 143 responded that they indulge do exercise. Mean duration of exercise per day in these 143 participants was $37.65 \pm 22.98$ min and mean number of days of exercise were $4.89 \pm$ 1.69 (Table-II).

Table-I: Socio-demographic profile of the respondents (n=332).

\begin{tabular}{|c|c|c|c|}
\hline \multicolumn{2}{|l|}{ Parameters } & \multicolumn{2}{|c|}{$\mathrm{n}(\%)$} \\
\hline \multicolumn{4}{|l|}{ Gender } \\
\hline \multicolumn{2}{|l|}{ Male } & \multicolumn{2}{|c|}{$109(33)$} \\
\hline \multicolumn{2}{|l|}{ Female } & \multicolumn{2}{|c|}{$223(67)$} \\
\hline \multicolumn{4}{|l|}{ Age in Years } \\
\hline \multicolumn{2}{|l|}{$17-20$ years } & \multicolumn{2}{|c|}{$127(38)$} \\
\hline \multicolumn{2}{|l|}{ 21-24 years } & \multicolumn{2}{|c|}{$205(61)$} \\
\hline \multicolumn{2}{|l|}{$>24$ years } & \multicolumn{2}{|c|}{$4(1)$} \\
\hline \multicolumn{4}{|l|}{ Specialty Distribution } \\
\hline \multicolumn{2}{|l|}{ MBBS } & \multicolumn{2}{|c|}{$256(77)$} \\
\hline \multicolumn{2}{|l|}{ BDS } & \multicolumn{2}{|c|}{$30(9)$} \\
\hline \multicolumn{2}{|l|}{ D-Pharmacy } & \multicolumn{2}{|c|}{$31(9.3)$} \\
\hline \multicolumn{2}{|l|}{ DPT } & \multicolumn{2}{|c|}{$15(5)$} \\
\hline \multicolumn{4}{|c|}{ Family History of Hypertension } \\
\hline \multicolumn{2}{|l|}{ Positive } & \multicolumn{2}{|c|}{$167(50.3)$} \\
\hline \multicolumn{2}{|l|}{ Negative } & \multicolumn{2}{|c|}{$165(49.7)$} \\
\hline \multicolumn{4}{|c|}{$\begin{array}{l}\text { Table-II: Mean and standard deviation of personal } \\
\text { characteristics of respondents }(n=332) \text {. }\end{array}$} \\
\hline Parameters & Mean \pm SD & Minimum & Maximum \\
\hline $\begin{array}{l}\text { Age of respondents } \\
\text { in years }\end{array}$ & $\begin{array}{l}21.06 \pm 1.53 \\
\text { years }\end{array}$ & 17 & 27 \\
\hline $\begin{array}{l}\text { Sitting systolic } \\
\text { BP of respondents }\end{array}$ & $\begin{array}{c}117.5 \pm \\
8.24 \mathrm{~mm} \mathrm{Hg}\end{array}$ & 100 & 150 \\
\hline $\begin{array}{l}\text { Sitting diastolic BP of } \\
\text { respondents }\end{array}$ & $\begin{array}{c}77.9 \pm \\
7.05 \mathrm{~mm} \mathrm{Hg}\end{array}$ & 60 & 110 \\
\hline $\begin{array}{l}\text { Weight of respondents } \\
\text { in } \mathrm{kg}\end{array}$ & $\begin{array}{l}62.77 \pm \\
12.60 \mathrm{~kg}\end{array}$ & 40 & 110 \\
\hline $\begin{array}{l}\text { Height of respondents } \\
\text { in meters }\end{array}$ & $1.65 \pm 0.11 \mathrm{~m}$ & 1.28 & 1.92 \\
\hline BMI of respondents & $22.78 \pm 3.96$ & 14.5 & 38.68 \\
\hline $\begin{array}{l}\text { Duration per } \\
\text { day spent in exercise in } \\
\text { minutes }(n=143)\end{array}$ & $\begin{array}{c}37.65 \pm \\
22.98 \mathrm{~min}\end{array}$ & 10 & 120 \\
\hline $\begin{array}{l}\text { No. of days exercised } \\
\text { in a week }(n=143)\end{array}$ & $\begin{array}{l}4.89 \pm 1.69 \\
\text { days }\end{array}$ & 1 & 7 \\
\hline
\end{tabular}

Results showed that out of 332 students, 5 (1.5\%) students had systolic BP above $140 \mathrm{mmHg}$ and were labelled as hypertensive after three different readings in different occasions on follow up. While readings of diastolic BP revealed that $34(10.2 \%)$ had sitting diastolic $\mathrm{BP}>90 \mathrm{~mm} \mathrm{Hg}$. 
Pearson correlation test was applied to assess the relationship of factors affecting systolic and diastolic BP of participants. Significant association was found between weight and both Systolic $(p<0.001)$ and Diastolic $(p=0.054)$ BP. BMI was also significantly associated with high blood pressures. Significant association is found between BP and exercise with number of days and duration of exercise (Table-III).

Table-III: Correlation of factors affecting systolic and diastolic blood pressure.

\begin{tabular}{l|c|c|c|c}
\hline \multirow{2}{*}{ Correlations } & \multicolumn{2}{|c|}{$\begin{array}{c}\text { Systolic Blood } \\
\text { Pressure }\end{array}$} & \multicolumn{2}{c}{$\begin{array}{c}\text { Diastolic Blood } \\
\text { Pressure }\end{array}$} \\
\cline { 2 - 5 } & $\mathbf{r}$ & $p$-value & r & $p$-value \\
\hline $\begin{array}{l}\text { Correlation with } \\
\text { weight }\end{array}$ & 1 & $<0.001$ & 0.106 & 0.054 \\
\hline $\begin{array}{l}\text { Correlation with } \\
\text { Height }\end{array}$ & -0.004 & 0.946 & -0.078 & 0.154 \\
\hline $\begin{array}{l}\text { Correlation with } \\
\text { BMI }\end{array}$ & 1 & $<0.001$ & 0.145 & 0.008 \\
\hline $\begin{array}{l}\text { Correlation with } \\
\text { Duration of } \\
\text { Exercise / day min }\end{array}$ & -0.138 & 0.010 & -0.169 & 0.043 \\
\hline $\begin{array}{l}\text { Correlation with } \\
\text { number of days in } \\
\text { week }\end{array}$ & -0.156 & 0.050 & -0.115 & 0.002 \\
\hline $\begin{array}{l}\text { Correlation with } \\
\text { age in years }\end{array}$ & 0.068 & 0.214 & 0.007 & 0.898 \\
\hline
\end{tabular}

Scatter diagram shown predict the correlations of systolic and diastolic blood pressure with weight and BMI of the participants (Figure-1 \& 2).

\section{DISCUSSION}

In recent years, hypertension has shown tremendous increase in prevalence in younger population worldwide. ${ }^{12}$ In this study, results showed that prevalence of systolic hypertension was $1.4 \%$ and diastolic hypertension was $10.4 \%$ in medical students. In a recent study of Libya, pre-HTN was detected in $27.1 \%$ of the students and hypertension in $2.2 \%$ of the students. ${ }^{13}$ A similar study was conducted in university students of Malaysia, which showed that $8.2 \%$ of the students had hypertension. Study showed that mean systolic blood pressure was $119.1 \mathrm{mmHg}$ with standard deviation of 14.36 and the mean diastolic blood pressure was $72.6 \mathrm{mmHg}$ with Standard Deviation of 9.73.14 In a study conducted in medical students of Saudi Arabia, hypertension was detected in $1.5 \%$ of the male students but prehypertension was detected with much higher rates where $52.1 \%$ of females and $58.8 \%$ of males, in undergraduate medical school were prehypertensive. ${ }^{15}$
Multiple factors play a key role in the development of hypertension. Findings of this study showed results where high blood pressure is associated with weight. A study was conducted in medical students of Saudi Arabia to assess the co-morbidities associated with obesity. Almost $11 \%$ of the obese medical students were identified to have hypertension. ${ }^{16}$

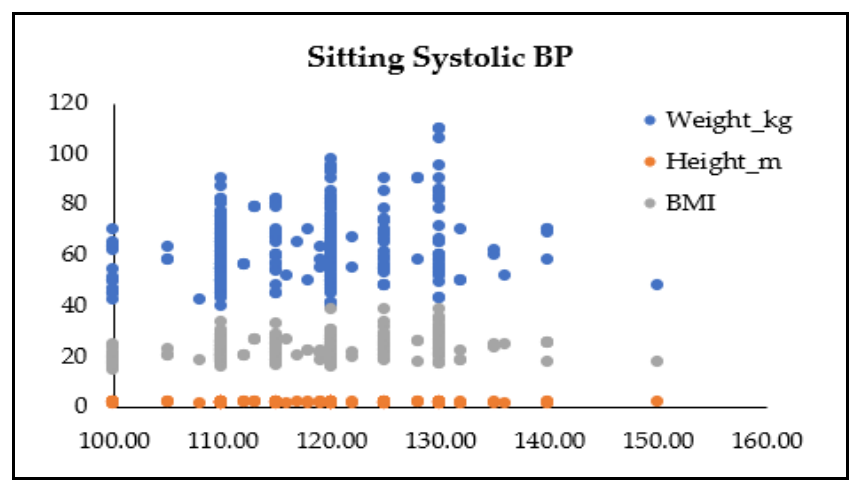

Figure-1: Correlation of sitting systolic blood pressure with weight and body mass index $(n=332)$.

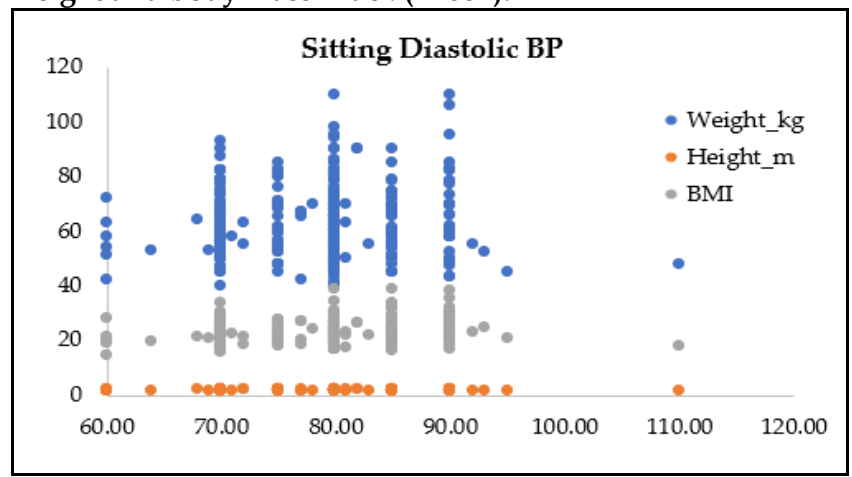

Figure-II: Correlation of sitting diastolic blood pressure with weight and body mass index $(n=332)$.

Results of this study showed no association with height of students with their systolic and diastolic blood pressure. Literature reveals that A $10 \mathrm{~cm}$ increase in height was related to a 7\%-point reduction in hypertension in growing population. Stronger relationship was revealed in adult population. ${ }^{17}$

Another strong predictor of high blood pressure is BMI. Results of this study revealed positive correlation between the two. Similar findings were obtained from different studies which depicted stronger positive correlation of BMI with development of hypertension. 18,19 Another factor which affects the prevalence of hypertension is life style. It is now a documented fact that regular exercise prevents hypertension by disrupting the correlation between sympathetic activity and agerelated increasing blood pressure. ${ }^{20} \mathrm{~A}$ strong negative correlation was observed with number of days of 
exercise and duration of exercise with raised blood pressure in this study. Results of meta-analysis showed similar findings. ${ }^{21}$ With incorporation of healthy life style, in terms of regular exercise hypertension can be prevented as well as it can reduce blood pressure in hypertensive patients.

\section{CONCLUSION}

Strong positive correlation was observed between obesity and BMI with hypertension. Regular exercise and longer duration of exercise are negatively correlated with blood pressure.

\section{ACKNOWLEDGEMENT}

Authors acknowledge the efforts of Dr Fuad Hameed Rai, (Assistant Professor, Community Medicine, Akhtar Saeed Medical and Dental college, Lahore) who supervised data collection for this project.

\section{Conflict of Interest: None.}

\section{Authors' Contribution}

IM: Conception, data analysis, writing, AM: Methodology, IM: Data collection, literature review.

\section{REFERENCES}

1. Khong TK. Hype and hope of bedtime dosing of antihypertensives: better to sleep on it. Drug Ther Bull 2020; 58(12): 178-182.

2. Bloch MJ. Worldwide prevalence of hypertension exceeds 1.3 billion. J Am Soc Hypertens 2016; 10(10): 753-754.

3. Sharman JE. Exercise blood pressure: clinical relevance and correct measurement. J Hum Hypertens 2015; 29(6): 351-358.

4. Carpio-Rivera E, Moncada-Jiménez J, Salazar-Rojas W, SoleraHerrera A. Acute effects of exercise on blood pressure: a metaanalytic investigation. Arq Bras Cardiol 2016; 106(5): 422-33.

5. Berger A, Grossman E, Katz M, Kivity S. Exercise blood pressure and the risk for future hypertension among normotensive middle aged adults. J Am Heart Assoc 2015; 4(4): e001710.

6. Okoh BA, Alikor EA, Akani N. Prevalence of hypertension in primary school-children in Port Harcourt, Nigeria. Paediatr Int Child Health 2012; 32(4): 208-212.

7. Helelo TP, Gelaw YA, Adane AA. Prevalence and associated factors of hypertension among adults in Durame Town, Southern Ethiopia. PloS one 2014; 9(11): e112790.

8. Abebe SM, Berhane Y, Worku A. Prevalence and associated factors of hypertension: a crossectional community based study in Northwest Ethiopia. PloS one 2015; 10(4): e0125210.
9. Neupane D, McLachlan CS, Sharma R, Gyawali B, Khanal V, Mishra SR, et al. Prevalence of hypertension in member countries of South Asian Association for Regional Cooperation (SAARC): systematic review and meta-analysis. Med 2014; 93(13): e74.

10. Leung AA, Nerenberg $K$, Daskalopoulou SS, McBrien $K$ Zarnke KB, Dasgupta K, et al. Hypertension Canada's 2016 Canadian hypertension education program guidelines for blood pressure measurement, diagnosis, assessment of risk, prevention, and treatment of hypertension. Can J Cardiol 2016; 32(5): 569-588.

11. Vuvor F. Correlation of body mass index and blood pressure of adults of 30-50 years of age in Ghana. J Health Res Rev 2017; 4(3): 115-118.

12. Martins Mdo $\mathrm{C}$, Icarte $\mathrm{IF}$, Rocha $\mathrm{CH}$, Maia $\mathrm{RB}$, Silva VB, Veras $A B$, et al. Blood pressure, excess weight and level of physical activity in students of a public university. Arq Bras Cardiol 2010; 95(2): 192-199.

13. Tayem YI, Yaseen NA, Khader WT, Abu Rajab LO, Ramahi AB, Saleh MH. Prevalence and risk factors of obesity and hypertension among students at a central university in the West Bank. Libyan J Med 2012; 7(1): 19222.

14. Cheah WL, Ensayan JM, Helmy H, Chang CT. Hypertension and its association with Anthropometric indices among students in a public university. Malays Fam Physician: J Acad Fam Physician Malays 2018; 13(1): 2-9.

15. Alanazi AM, Alenezi YM, Alanazi TH, Alruwaili BA, Alanazi AM, Alrawili AN et al. Prehypertension and hypertension in medical students of Northern Border University in Arar, Saudi Arabia. Egypt J Hosp Med 2018; 70(1): 33-38.

16. Mehmood Y, Al-Swailmi FK, Al-Enazi SA. Frequency of obesity and comorbidities in medical students. PaK J Med Sci 2016; 32(6): 1528.

17. Sohn K. The association between height and hypertension in Indonesia. Econ Hum Biol 2017; 27(1): 74-83.

18. Decoda Study Group, Nyamdorj R. BMI compared with central obesity indicators in relation to diabetes and hypertension in Asians. Obesity 2008; 16(7): 1622-1635.

19. Feng RN, Zhao C, Wang C, Niu YC, Li K, Guo FC, et al. BMI is strongly associated with hypertension, and waist circumference is strongly associated with type 2 diabetes and dyslipidemia, in northern Chinese adults. J Epidemiol 2012; 22(4): 317-323.

20. Li JY, Chen CW, Liu TH, Kuo TB, Yang CC. Exercise prevents hypertension and disrupts the correlation between vascular sympathetic activity and age-related increase in blood pressure in SHRs. Am J Hypertens 2019; 32(11): 1091-1100.

21. Pescatello LS, Franklin BA, Fagard R, Farquhar WB, Kelley GA, Ray CA. Exercise and hypertension. Med Sci Sports Exerc 2004; 36(3): 533-553. 